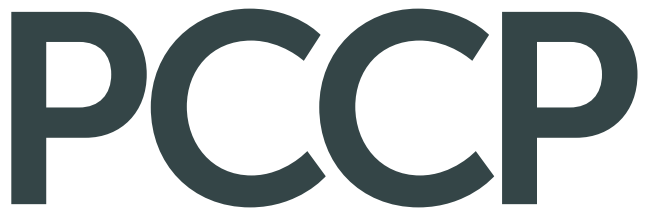

Physical Chemistry Chemical Physics www.rsc.org/pccp

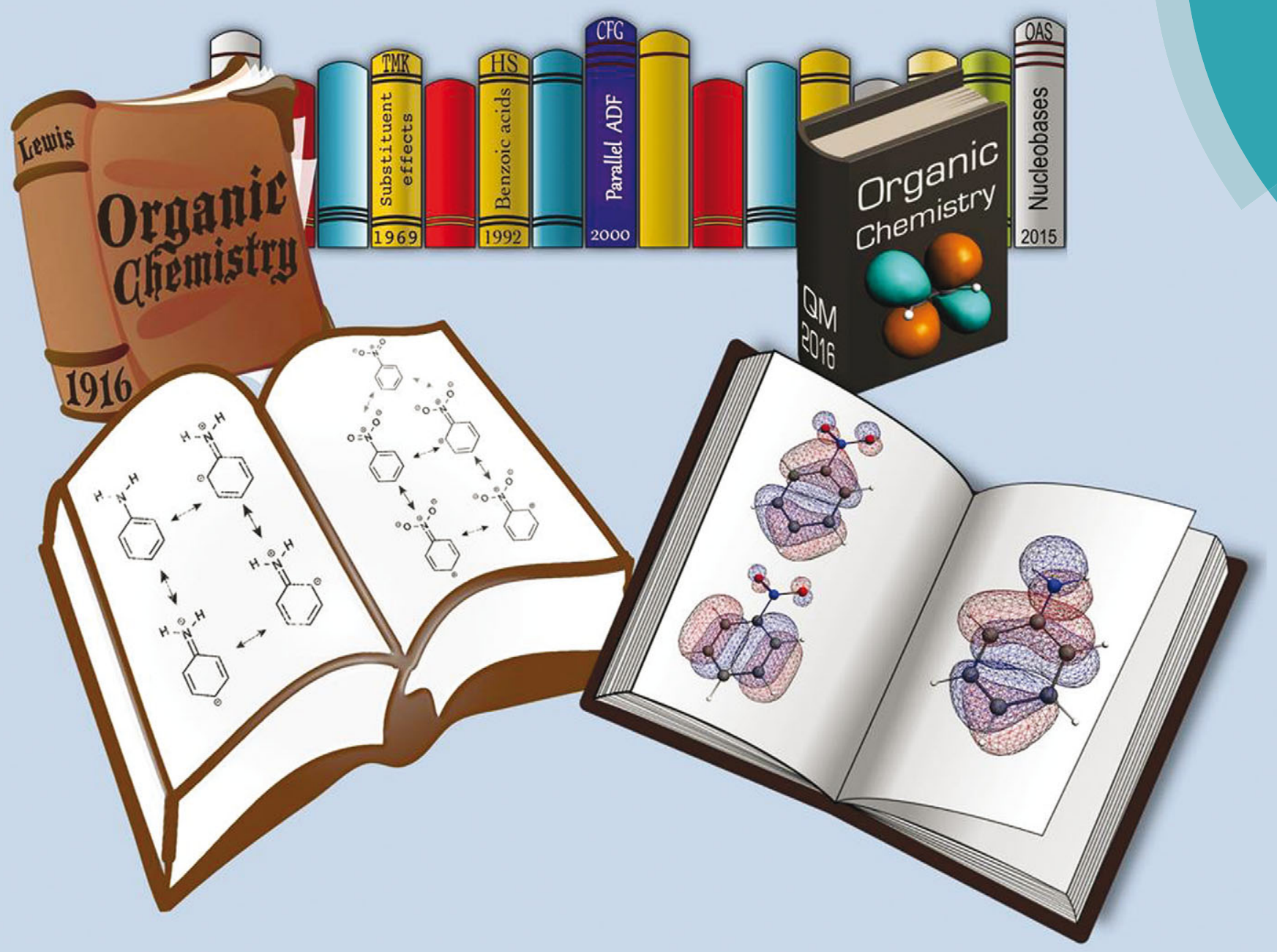

Themed issue: Electron delocalization and aromaticity: 150 years of the Kekulé benzene structure

ISSN 1463-9076

\section{PAPER}

C. Fonseca Guerra et al.

How amino and nitro substituents direct electrophilic aromatic substitution

in benzene: an explanation with Kohn-Sham molecular orbital theory and

Voronoi deformation density analysis

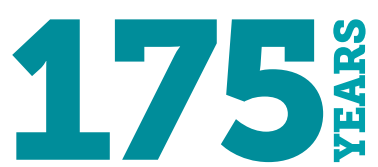




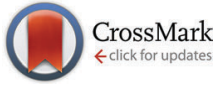

Cite this: Phys. Chem. Chem. Phys., 2016, 18, 11624

Received 4th December 2015, Accepted 14th January 2016

DOI: $10.1039 / c 5 c p 07483 e$

www.rsc.org/pccp

\title{
How amino and nitro substituents direct electrophilic aromatic substitution in benzene: an explanation with Kohn-Sham molecular orbital theory and Voronoi deformation density analysis $\uparrow$
}

\author{
O. A. Stasyuk, ${ }^{a}$ H. Szatylowicz, ${ }^{a}$ T. M. Krygowski ${ }^{\mathrm{b}}$ and C. Fonseca Guerra* ${ }^{\mathrm{c}}$
}

\begin{abstract}
The substituent effect of the amino and nitro groups on the electronic system of benzene has been investigated quantum chemically using quantitative Kohn-Sham molecular orbital theory and a corresponding energy decomposition analysis (EDA). The directionality of electrophilic substitution in aniline can accurately be explained with the amount of contribution of the $2 \mathrm{p}_{z}$ orbitals on the unsubstituted carbon atoms to the highest occupied $\pi$ orbital. For nitrobenzene, the molecular $\pi$ orbitals cannot explain the regioselectivity of electrophilic substitution as there are two almost degenerate $\pi$ orbitals with nearly the same $2 p_{z}$ contributions on the unsubstituted carbon atoms. The Voronoi deformation density analysis has been applied to aniline and nitrobenzene to obtain an insight into the charge rearrangements due to the substituent. This analysis method identified the orbitals involved in the $\mathrm{C}-\mathrm{N}$ bond formation of the $\pi$ system as the cause for the $\pi$ charge accumulation at the ortho and para positions in the case of the $\mathrm{NH}_{2}$ group and the largest charge depletion at these same positions for the $\mathrm{NO}_{2}$ substituent. Furthermore, we

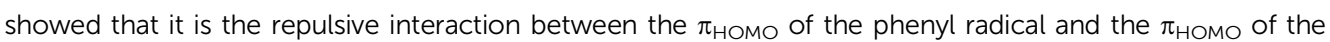
$\mathrm{NH}_{2}$ radical that is responsible for pushing up the $\pi_{\text {Номо }}$ of aniline and therefore activating this $\pi$ orbital of the phenyl ring towards electrophilic substitution.
\end{abstract}

\section{Introduction}

In modern organic chemistry textbooks an explanation of the chemical reactivity of the benzene ring in electrophilic aromatic substitution is directly connected with electron-donating or electron-withdrawing influence of substituents on the electronic system. The explanation is not relying on modern quantitative computational techniques, but quite often on the concepts of Lewis from $1916,{ }^{1 e}$ where the electrons are thought to be at an intermediate state between different resonance structures (see Scheme 1). ${ }^{1}$ This, however, does not describe what happens quantum chemically in the electronic system. The effect of the substituent on the reactivity of the benzene ring can be divided

\footnotetext{
${ }^{a}$ Faculty of Chemistry, Warsaw University of Technology, Noakowskiego 3, Warsaw 00-664, Poland

${ }^{b}$ Department of Chemistry, University of Warsaw, Pasteura 1, 02-093 Warsaw, Poland

${ }^{c}$ Department of Theoretical Chemistry and Amsterdam Center for Multiscale Modeling, Vrije Universiteit Amsterdam, De Boelelaan 1083, 1081 HV Amsterdam, The Netherlands. E-mail: c.fonsecaguerra@vu.nl

$\dagger$ Electronic supplementary information (ESI) available: MO diagrams for nitrobenzene and aniline in a perpendicular orientation; interaction energies and rotational barriers for substituted benzenes; and Cartesian coordinates of nitrobenzene and aniline at the BLYP/TZ2P level. See DOI: 10.1039/c5cp07483e
}

into the field/inductive effect and the resonance (or mesomeric) effect. ${ }^{1}$ The main problem is to determine individual contributions of each effect for a particular substituent. ${ }^{2}$ When the resonance and field effects act in the same direction, their separation becomes even more difficult. Undoubtedly, the classical Hammett approach ${ }^{3}$ (proposed in 1937) expressed by the $\sigma$ substituent constants has been the first attempt of a quantitative description of the substituent effects. Also this approach, based on experimental data on benzoic acid derivatives, is still widely used in chemistry. To date, different quantitative characteristics are also used to estimate contributions of inductive and resonance effects but they are not general and usually depend on the kind of studied systems. ${ }^{4}$ It is known that the inductive effect operates through $\sigma$-bonds, while the resonance effect is transmitted through $\pi$-electrons. Lewis structures, which can be seen as a qualitative application of the valence bond theory, are used to explain activating or deactivating substituent properties and also to predict a favored product of the electrophilic attack. A more rigorous way to describe a relationship between molecular structure and electron density is the analysis using qualitative molecular orbitals. ${ }^{1 a, d, 5}$

In this work, we would like to study the substituent effects of $\mathrm{NH}_{2}$ and $\mathrm{NO}_{2}$ groups on benzene using Kohn-Sham density functional theory. As is known, these two substituents have 

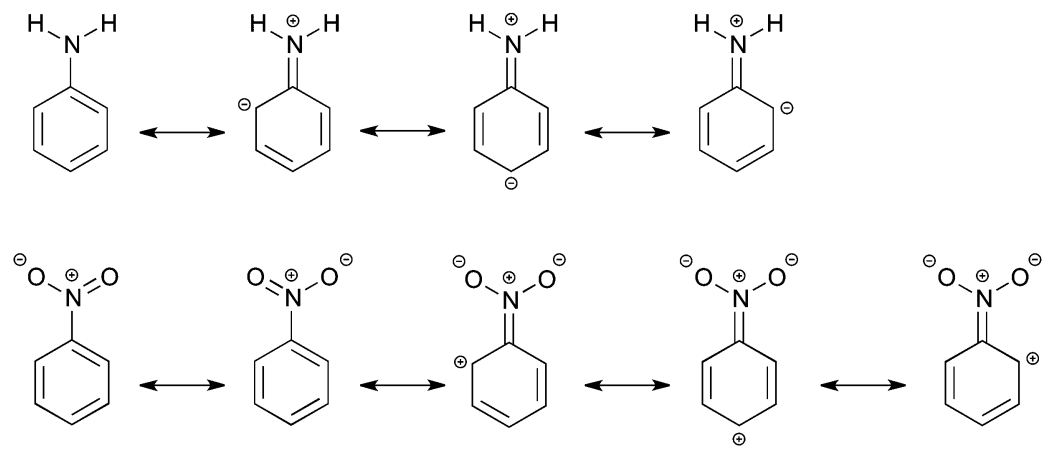

Scheme 1 Resonance structures of aniline and nitrobenzene.

completely opposite electronic properties and therefore, opposite effects on the electrophilic substitution reactions of benzene. ${ }^{1}$ The amino group is activating and ortho- and para-directing, whereas the nitro substituent is known to be deactivating and meta-directing. This difference in reactivity can be made plausible by the Lewis structures of aniline and nitrobenzene (Scheme 1), but it does not give an explanation of the influence of the substituent on the molecular $\sigma$ and $\pi$ orbitals located on the phenyl ring. The resonance structures suggest that the amino group increases the electron density only at ortho- and para-positions of the ring, making them more preferred to the electrophilic attack. In turn, the nitro group, according to the resonance structures, promotes the formation of a meta-product by decreasing the $\pi$-electron density at the ortho and para positions (Scheme 1). The field effect was deduced to be also important for the nitro substituent and to explain its deactivating properties. ${ }^{1 a, 6 a}$ In previous studies, ${ }^{6 b-d}$ some attempts were done to separate the total substituent effect of the nitro group into $\sigma$ - and $\pi$-contributions. However, the outcome was not conclusive, in particular about an importance of the resonance effect, that is the directing effect, in nitrobenzene.

In this study, the resonance and inductive effects of the substituents on the benzene ring are analyzed and separated using Kohn-Sham Molecular Orbital (KS-MO) theory and the accompanying Energy Decomposition Analysis ${ }^{7}$ (EDA). The quantitative KS-MO model together with the EDA have proven to be able to elucidate the nature of different types of bonds: the nature of resonance-assisted hydrogen bonding ${ }^{8}$ and halogen bonding ${ }^{9}$ has been defined. Moreover, the KS-MO model was successfully used for explaining the organic reaction mechanism, ${ }^{10}$ the concept of aromaticity and other properties of chemical compounds. ${ }^{11}$ This method uses symmetry which allows separating the interactions into $\sigma$ - and $\pi$-electronic systems of the benzene ring and the substituents. Previously, Fernandez et al. ${ }^{11 d}$ found a correlation between the Hammett constants and the $\pi$ electronic energy term. We will also use the Voronoi Deformation Density (VDD) charge analysis, which enables us to track the reorganization in the $\sigma$ and $\pi$ electron densities of the phenyl ring due to the substituent and to determine the resonance and inductive effects on the ring. Based on frontier molecular orbital theory to explain chemical reactivity, our quantitative KS-MO results together with the VDD charges clarify the orientation of the electrophilic aromatic substitution and the change in reactivity of the benzene ring caused by the $\mathrm{NH}_{2}$ or $\mathrm{NO}_{2}$ substituents.

\section{Methodology}

\section{General procedure}

All calculations were carried out using the Amsterdam Density Functional (ADF) program. ${ }^{12}$ Geometries and energies were calculated using the generalized gradient approximation (GGA) with the BLYP functional. ${ }^{12 c, d}$ The MOs were expanded in uncontracted sets of Slater type orbitals (STOs) containing diffuse functions with two sets of polarization functions (TZ2P). ${ }^{12 e}$ The $1 \mathrm{~s}$ core shells of carbon, nitrogen and oxygen were treated by the frozen-core approximation. Geometries were optimized in the gas phase assuming $C_{2 \mathrm{v}}$ symmetry (the difference in energy of the amino group between planar and pyramidal geometries is only $0.3 \mathrm{kcal} \mathrm{mol}^{-1}$, see also ref. 13).

\section{Energy decomposition analysis}

To analyze the effect of the substituent on the benzene ring, we defined two fragments consisting of two radicals with opposite spins, which are combined into aniline or nitrobenzene (see Scheme 2). The fragments are treated in the KS open-shell restricted formalism as proposed in ref. $7 a$.

The interaction energy is examined in the substituted benzene in the framework of the KS-MO model using a quantitative energy decomposition analysis (EDA $)^{7 a}$ into electrostatic interactions, Pauli repulsive orbital interactions and attractive orbital interactions:

$$
\Delta E_{\text {int }}=\Delta V_{\text {elstat }}+\Delta E_{\text {Pauli }}+\Delta E_{\text {oi }}
$$

The term $\Delta V_{\text {elstat }}$ corresponds to the classical electrostatic interaction between the unperturbed charge distributions of the distorted fragments and is usually attractive. The Pauli repulsion energy, $\Delta E_{\text {Pauli }}$, comprises the destabilizing interactions between the occupied orbitals and is responsible for the steric repulsion. The orbital interaction energy, $\Delta E_{\mathrm{o}}$, represents the donor-acceptor

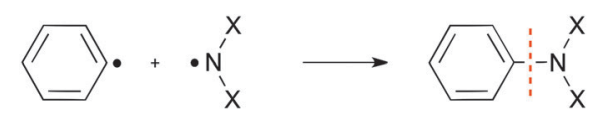

Scheme 2 Fragment decomposition of substituted benzenes $(X=O, H)$. 
interactions between the occupied molecular orbitals on one fragment with the unoccupied molecular orbitals of the other fragment, the electron-pair bond formation, as well as the mixing of occupied and virtual orbitals within the same fragment.

The orbital interaction energy can be further decomposed into the contributions from each irreducible representation $\Gamma$ of the interacting system (eqn (2)): ${ }^{7}$

$$
\Delta E_{\mathrm{oi}}=\Delta E_{\sigma}+\Delta E_{\pi}
$$

Both nitrobenzene and aniline have $C_{2 \mathrm{v}}$ symmetry, which decomposes $\Delta E_{\sigma}$ into $\Delta E_{\mathrm{A} 1}+\Delta E_{\mathrm{B} 2}$ and $\Delta E_{\pi}$ into $\Delta E_{\mathrm{A} 2}+\Delta E_{\mathrm{B} 1}$ components.

\section{Analysis of the charge distribution}

The Voronoi Deformation Density ${ }^{14}$ (VDD) atomic charges for aniline and nitrobenzene have also been computed. The VDD charge $Q_{\mathrm{A}}$ is computed as the (numerical) integral of the deformation density $\Delta \rho(\mathbf{r})$ associated with the formation of the molecule from its atoms in the volume of the Voronoi cell of atom A (eqn (3)). The Voronoi cell of an atom A is defined as the compartment of space bound by the bond midplanes on and perpendicular to all bond axes between the nucleus A and its neighboring nuclei.

$$
Q_{\mathrm{A}}=-\int_{\text {Voronoi cell of A }}\left(\rho(\mathbf{r})-\sum_{\mathrm{B}} \rho_{\mathrm{B}}(\mathbf{r})\right) \mathrm{d} \mathbf{r}
$$

Here, $\rho(\mathbf{r})$ is the electron density of the molecule and the sum over $\rho_{\mathrm{B}}(\mathbf{r})$ is the superposition of atomic densities $\rho_{\mathrm{B}}$ of a fictitious promolecule without chemical interactions that is associated with the situation in which all atoms are neutral. $Q_{\mathrm{A}}$ directly monitors how much charge flows, due to chemical interactions, out of $\left(Q_{\mathrm{A}}>0\right)$ or into $\left(Q_{\mathrm{A}}<0\right)$ the Voronoi cell of atom $\mathrm{A}$, that is, the region of space that is closer to nucleus $\mathrm{A}$ than to any other nucleus.

The VDD method also allows us to analyze the electronic redistributions within two polyatomic fragments when a chemical bond is formed between these two molecular fragments. Previously, we have shown that this method is most informative to analyze resonance-assisted hydrogen bonding appropriately as it allows decomposition of the total changes into $\sigma$ and $\pi$ electronic rearangements. $^{8 a, b}$ The change in VDD atomic charges $\Delta Q_{\mathrm{A}}$ is defined by eqn (4), which relates this quantity directly to the deformation density $\rho_{\mathrm{Ph}-\mathrm{NX}_{2}}(\mathbf{r})-\rho_{\mathrm{Ph}} \bullet(\mathbf{r})-\rho_{\mathrm{NX}_{2}}(\mathbf{r})$ associated with the formation of the overall molecule from the two fragments $\mathrm{Ph}^{\bullet}$ and ${ }^{\bullet} \mathrm{NX}_{2}$ (with $\mathrm{X}=\mathrm{H}$ or $\mathrm{O}$ ). ${ }^{8 a, b, 14}$

$$
\Delta Q_{\mathrm{A}}=-\int_{\text {Voronoi cell of } \mathrm{A} \text { in } \mathrm{Ph}-\mathrm{NX}_{2}}\left(\rho_{\mathrm{Ph}-\mathrm{NX}_{2}}(\mathbf{r})-\rho_{\mathrm{Ph}} \bullet(\mathbf{r})-\rho_{\bullet \mathrm{NX}_{2}}(\mathbf{r})\right) \mathrm{d} \mathbf{r}
$$

$\Delta Q_{\mathrm{A}}$ monitors how much charge flows out of $\left(\Delta Q_{\mathrm{A}}>0\right)$ or into $\left(\Delta Q_{\mathrm{A}}<0\right)$ the Voronoi cell of atom $\mathrm{A}$ as a result of the chemical bond formation between fragments $\mathrm{Ph}^{\bullet}$ and ${ }^{\bullet} \mathrm{NX}_{2}$ in the substituted benzene.
This functionality is extended by the decomposition into $\sigma$ and $\pi$ components (for the planar, $C_{\mathrm{s}}$ symmetric molecules):

$$
\begin{aligned}
& \Delta Q_{\mathrm{A}}^{\sigma / \pi} \\
& =-\int_{\text {Voronoi cell of A in } \mathrm{Ph}-\mathrm{NX}_{2}}\left(\rho_{\mathrm{Ph}-\mathrm{NX}_{2}}^{\sigma / \pi}(\mathbf{r})-\rho_{\mathrm{Ph}}^{\sigma / \pi}(\mathbf{r})-\rho_{\bullet \mathrm{NX}_{2}}^{\sigma / \pi}(\mathbf{r})\right) \mathrm{d} \mathbf{r}
\end{aligned}
$$

For the $\pi$ system, this functionality is additionally extended by the decomposition of the electronic redistribution per atom $\Delta Q_{\mathrm{A}}$ into a component associated with the Pauli repulsion $\Delta E_{\text {Pauli }}$ and a component associated with the bonding orbital interactions $\Delta E_{\mathrm{oi}}$.

$$
\Delta Q_{\mathrm{A}}^{\pi}=\Delta Q_{\mathrm{A}, \text { Pauli }}^{\pi}+\Delta Q_{\mathrm{A}, \mathrm{oi}}^{\pi}
$$

This $\pi$ charge decomposition constitutes a bond analysis tool that mirrors the $\pi$ term of the $\Delta E_{\text {Pauli }}$ and $\Delta E_{\text {oi }}$ terms occurring in the bond energy decomposition of eqn (1) and (2) (note that $\Delta V_{\text {elstat }}$ is not associated with any charge redistribution). This can be obtained by writing the deformation density of $\pi$ electronic systems as follows:

$$
\Delta \rho^{\pi}(\mathbf{r})=\Delta \rho_{\text {Pauli }}^{\pi}(\mathbf{r})+\Delta \rho_{\text {oi }}^{\pi}(\mathbf{r})
$$

The change in $\pi$ atomic charge caused by Pauli repulsion between the monomers in the complex is defined by eqn (8), and the corresponding change caused by charge transfer and polarization is given by eqn (9).

$$
\begin{aligned}
& \Delta Q_{\mathrm{A}, \text { Pauli }}^{\pi} \\
& =-\int_{\text {Voronoi cell of } \mathrm{A} \text { in } \mathrm{Ph}-\mathrm{NX}_{2}}\left(\rho_{\mathrm{Ph}-\mathrm{NX}_{2}}^{0, \pi}(\mathbf{r})-\rho_{\mathrm{Ph}}^{\pi} \cdot(\mathbf{r})-\rho_{\bullet}^{\pi} \mathrm{NX}_{2}\right. \\
&
\end{aligned}
$$

$$
\Delta Q_{\mathrm{A}, \mathrm{oi}}^{\pi}=-\int_{\text {Voronoi cell of } \mathrm{A} \text { in } \mathrm{Ph}-\mathrm{NX}_{2}}\left(\rho_{\mathrm{Ph}-\mathrm{NX}_{2}}^{\pi}(\mathbf{r})-\rho_{\mathrm{Ph}-\mathrm{NX}_{2}}^{0, \pi}(\mathbf{r})\right) \mathrm{d} \mathbf{r}
$$

The $\rho^{0}$ density is obtained from $\Psi_{\mathrm{Ph}-\mathrm{NX}_{2}}^{0}=N \hat{A}\left[\Psi_{\mathrm{Ph}} \bullet \Psi_{\mathrm{NX}_{2}}\right]$ through explicit anti-symmetrization ( $\hat{A}$ operator) and renormalization ( $N$ constant) of the product of monomer wave functions when the unperturbed monomer densities $\rho_{\mathrm{Ph}} \bullet+\rho_{\mathbf{N X}_{2}}$ are superimposed. The $\pi$ density $\rho^{\pi}$ is obtained as the sum of orbital densities of the occupied molecular orbitals belonging to the $A^{\prime \prime}$ irreducible representation (in $C_{\mathrm{s}}$ symmetry). As the molecular symmetry of aniline and nitrobenzene is $C_{2 \mathrm{v}}$, thus of higher symmetry than $C_{\mathrm{s}}$, the changes in the atomic charge can be split further into A2 and B1.

$$
\begin{gathered}
\Delta Q_{\mathrm{A}, \text { Pauli }}^{\pi}=\Delta Q_{\mathrm{A}, \text { Pauli }}^{\mathrm{A} 2}+\Delta Q_{\mathrm{A}, \text { Pauli }}^{\mathrm{B} 1} \\
\Delta Q_{\mathrm{A}, \mathrm{oi}}^{\pi}=\Delta Q_{\mathrm{A}, \mathrm{oi}}^{\mathrm{A} 2}+\Delta Q_{\mathrm{A}, \mathrm{oi}}^{\mathrm{B} 1}
\end{gathered}
$$

\section{Results and discussion}

\section{Energy decomposition analysis and bonding mechanism}

The energy decomposition analysis and the molecular orbital diagrams of the bonding mechanism in nitrobenzene and 
Table 1 Energy decomposition analysis (in kcal $\mathrm{mol}^{-1}$ ) of the $\mathrm{C}-\mathrm{N}$ bond for substituted benzenes from $\mathrm{Ph}^{\bullet}$ and $\bullet \mathrm{NX}_{2}($ with $\mathrm{X}=\mathrm{H}$ and $\mathrm{O}$ )

\begin{tabular}{|c|c|c|c|c|c|c|c|c|c|c|c|c|}
\hline $\mathrm{NX}_{2}$ & & $d(\mathrm{CN}) / \AA$ & $\Delta V_{\text {elstat }}$ & $\Delta E_{\text {Pauli }}$ & $\Delta E_{\sigma}{ }^{a}$ & $\Delta E_{\mathrm{A} 1}$ & $\Delta E_{\mathrm{B} 2}$ & $\Delta E_{\pi}^{a}$ & $\Delta E_{\mathrm{A} 2}$ & $\Delta E_{\mathrm{B} 1}$ & $\Delta E_{\mathrm{oi}}$ & $\Delta E_{\mathrm{int}}$ \\
\hline$\cdot \mathrm{NH}_{2}$ & 90 & 1.389 & -165.5 & 292.3 & -249.5 & -238.0 & -11.5 & -11.0 & -0.1 & -9.2 & -260.5 & -133.7 \\
\hline$\cdot \mathrm{NH}_{2}$ & 0 & 1.492 & -124.2 & 211.0 & -208.9 & -204.1 & -4.8 & -17.3 & -0.1 & -17.2 & -226.2 & -139.4 \\
\hline$\cdot \mathrm{NO}_{2}$ & 0 & 1.492 & -161.2 & 330.0 & -224.4 & -217.7 & -6.7 & -18.5 & -0.7 & -17.8 & -242.9 & -74.1 \\
\hline$\cdot \mathrm{NO}_{2}$ & 90 & 1.492 & -159.5 & 330.3 & -229.6 & -219.9 & -9.7 & -11.0 & -0.7 & -9.1 & -239.6 & -68.8 \\
\hline$\cdot \mathrm{NO}_{2}$ & 0 & 1.389 & -211.6 & 445.0 & -276.0 & -265.9 & -10.1 & -27.9 & -1.0 & -26.9 & -303.9 & -70.5 \\
\hline
\end{tabular}

${ }^{a} \Delta E_{\sigma}=\Delta E_{\mathrm{A} 1}+\Delta E_{\mathrm{B} 2}$ and $\Delta E_{\pi}=\Delta E_{\mathrm{A} 2}+\Delta E_{\mathrm{B} 1}$.

aniline between $\mathrm{Ph}^{\bullet}$ and ${ }^{\bullet} \mathrm{NX}_{2}$, obtained at the KS-DFT BLYP/ TZ2P level of theory, are displayed in Table 1 and Fig. 1 and 2 (only the most important interactions are represented).

The energy decomposition analysis of the electron-pair bond formation between $\mathrm{Ph}^{\bullet}$ and the substituent ${ }^{\bullet} \mathrm{NX}_{2}$ shows that interaction energy for the formation of nitrobenzene is about half of the formation of aniline $\left(-74.1 \mathrm{kcal} \mathrm{mol}^{-1}\right.$ and $-143.6 \mathrm{kcal} \mathrm{mol}^{-1}$, respectively) and the $\mathrm{C}-\mathrm{N}$ bond is also shorter in aniline than in nitrobenzene (1.389 $\AA$ and $1.492 \AA$, respectively). The longer $\mathrm{C}-\mathrm{N}$ distance in nitrobenzene is caused by the larger Pauli repulsion (330.0 kcal mol ${ }^{-1}$ for $\mathrm{Ph}-\mathrm{NO}_{2}$ and 288.5 for $\mathrm{Ph}-\mathrm{NH}_{2}$ ). Compression of the $\mathrm{C}-\mathrm{N}$ distance in nitrobenzene to the distance in aniline makes the Pauli repulsion go up from $330.0 \mathrm{kcal} \mathrm{mol}^{-1}$ to $445.0 \mathrm{kcal} \mathrm{mol}^{-1}$, whereas in aniline the Pauli repulsion is only $288.5 \mathrm{kcal} \mathrm{mol}^{-1}$ at
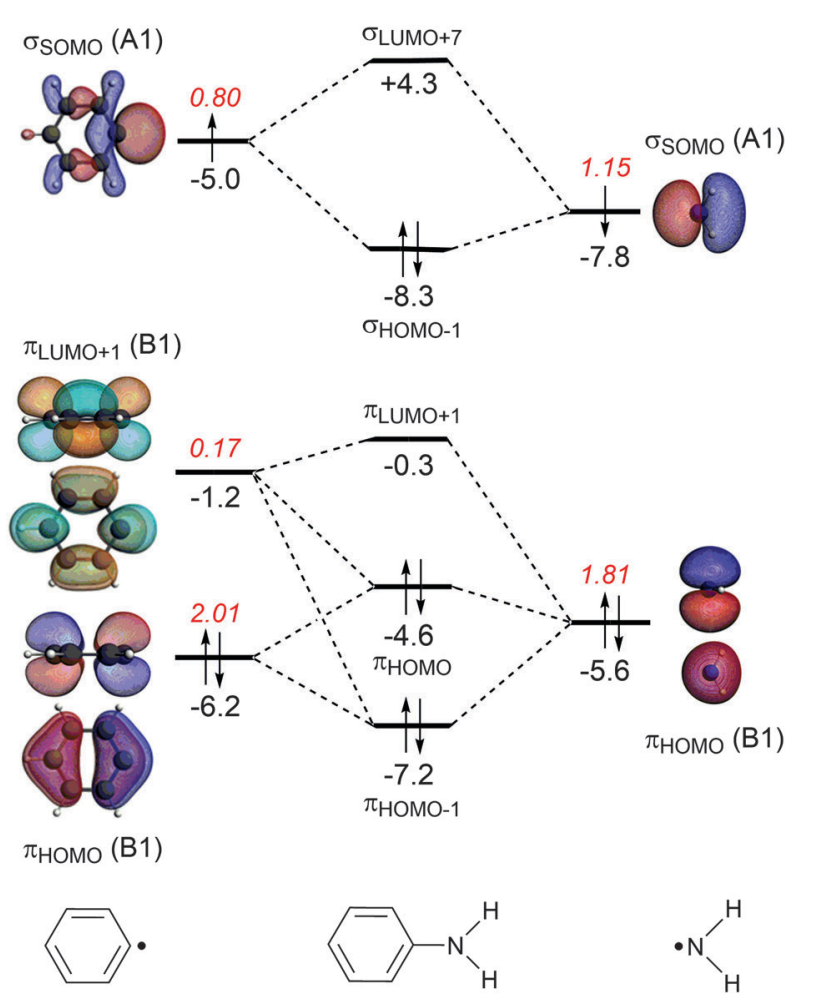

$\pi_{\text {HOMO }}(\mathrm{B} 1)$
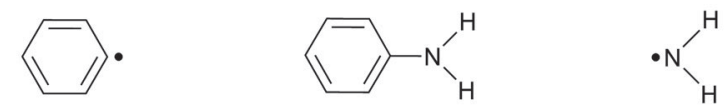

Fig. 1 MO diagrams for the $\mathrm{C}-\mathrm{N}$ bond formation from $\mathrm{Ph} \bullet$ and $\bullet \mathrm{NH}_{2}$ into aniline with the electron-pair formation in the $\sigma$ system (only A1 orbitals) at the top and the donor-acceptor interactions in the $\pi$ system (only B1 orbitals) at the bottom. The energies (eV) of the molecular or fragment orbitals are given in black and the gross electron population of the fragment orbitals in red.

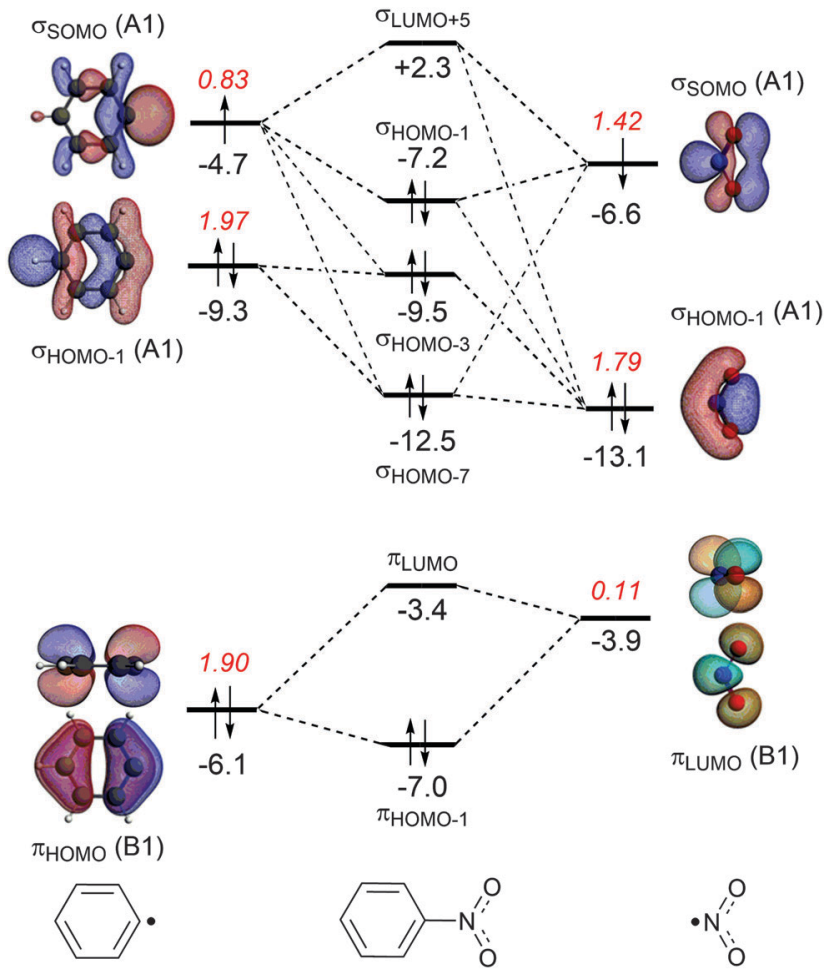

Fig. $2 \mathrm{MO}$ diagrams for the $\mathrm{C}-\mathrm{N}$ bond formation from $\mathrm{Ph} \bullet$ and $\bullet \mathrm{NO}_{2}$ into nitrobenzene with the electron-pair formation in the $\sigma$ system (only A1 orbitals) at the top and the donor-acceptor interactions in the $\pi$ system (only B1 orbitals) at the bottom. The energies (eV) of the molecular or fragment orbitals are given in black and the gross electron population of the fragment orbitals in red. (The $\sigma_{\text {HOMO }}$ on both fragments are of B2 orbitals, which do not overlap.)

1.389 $\AA$. The shortening of the $\mathrm{C}-\mathrm{N}$ distance in nitrobenzene results in an increase of $115.0 \mathrm{kcal}$ of the Pauli repulsion and only in an extra attraction of $-111.4 \mathrm{kcal} \mathrm{mol}^{-1}$ of the bonding components (electrostatic and orbital interaction). The $\sigma$ MO diagram shows the repulsive interaction between the occupied $\sigma_{\text {Hомо }-1}$ of $\mathrm{Ph}^{\bullet}$ and $\sigma_{\text {Hомо-1 }}$ of ${ }^{\bullet} \mathrm{NO}_{2}$, which is absent in the $\sigma$ MO diagram of aniline (see Fig. 1 and 2). The largest bonding contribution to the interaction energy is the A1 component of the orbital interaction (that is the formation of the electron-pair bond), which amounts to $-239.5 \mathrm{kcal} \mathrm{mol}^{-1}$ for aniline and $-217.7 \mathrm{kcal} \mathrm{mol}^{-1}$ for nitrobenzene. The electrostatic interaction is of similar strength for both systems: $-160.0 \mathrm{kcal} \mathrm{mol}^{-1}$ for aniline and $-161.2 \mathrm{kcal} \mathrm{mol}^{-1}$ for nitrobenzene. Note that the $\Delta E_{\mathrm{A} 2}$ and $\Delta E_{\mathrm{B} 2}$ only account for polarization within each fragment 
as the A2 and B2 orbitals have no amplitude on the atoms located on the $C_{2}$ rotation axis and therefore do not overlap.

The stabilization caused by the donor-acceptor interactions in the B1 irreducible representation (that is in the $\pi$ electronic system) is larger for aniline $\left(-24.9 \mathrm{kcal} \mathrm{mol}^{-1}\right)$ than for nitrobenzene $\left(-17.8 \mathrm{kcal} \mathrm{mol}^{-1}\right)$. Compression of the $\mathrm{C}-\mathrm{N}$ bond in $\mathrm{Ph}-\mathrm{NO}_{2}$ to the distance of $\mathrm{Ph}-\mathrm{NH}_{2}$ enlarges the $\Delta E_{\mathrm{B} 1}$ to $-26.9 \mathrm{kcal} \mathrm{mol}^{-1}$.

For both substituents, $\mathrm{NH}_{2}$ and $\mathrm{NO}_{2}$, the formation of the electron-pair bond in the $\sigma$ electronic system causes the singly occupied molecular orbital (SOMO) of the phenyl radical to donate 0.2 electrons to the SOMO of the substituent accounting for the inductive effect of the substituent. In the case of nitrobenzene, the bond formation is accompanied by the Pauli repulsive interaction between occupied orbitals on the $\mathrm{Ph}^{\bullet}$ and $\bullet \mathrm{NO}_{2}$ fragments (see Fig. 2).

The donor-acceptor interactions in the $\pi$ electronic system of aniline and nitrobenzene have an opposite effect on the phenyl radical: $\mathrm{NH}_{2}$ is electron donating and $\mathrm{NO}_{2}$ is electronwithdrawing. The MO diagrams illustrate this clearly. For aniline, the $\pi$-orbital of the $\mathrm{NH}_{2}$ group donates 0.17 electrons to the $\pi_{\mathrm{LUMO}+1}$ orbital of the benzene ring (see Fig. 1 ). This counteracts the charge-flow in the $\sigma$ system. There is also Pauli repulsion between the $\pi_{\text {Hомо }}$ on $\mathrm{Ph}^{\bullet}$ and ${ }^{\bullet} \mathrm{NH}_{2}$, which pushes up the energy of the $\pi_{\mathrm{HOMO}}$ of aniline to $-4.6 \mathrm{eV}$ and accounts for the activation towards electrophilic substitution and not the donor-acceptor interactions. This mechanism has also been encountered in the study of the substituent effects on the optical properties of naphthalene diimides. ${ }^{11 c}$

In the case of nitrobenzene, the electron transfer goes in the opposite direction. The $\pi_{\mathrm{LuMO}}$ of the $\mathrm{NO}_{2}$ group accepts 0.11 electrons from the $\pi$-system of the benzene ring increasing the deactivation for electrophilic substitution (see Fig. 2). The

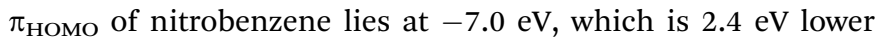
than the same orbital in aniline and explains the lower reactivity of nitrobenzene.

Another way to investigate the effect of the substituents is to rotate the substituents by 90 degrees, that is, perpendicular to the plane of the benzene ring and analyze the capability of the substituents to participate in the $\pi$-electron delocalization of the ring. The donor-acceptor interactions are either lost as in the nitrobenzene or become negligible as in aniline (the amino group donates only 0.03 electrons, see Fig. S1 and S2, ESI $\dagger$ ). Rotation of the substituent $\mathrm{NX}_{2}$ (the rotation barriers are given in Table S1, ESI $\dagger$ ) switches off the donor-acceptor interactions in the $\pi$ electronic system, however the energetic loss is quite small in both cases. For nitrobenzene, $\Delta E_{\pi}$ goes from $-18.5 \mathrm{kcal} \mathrm{mol}^{-1}$ to $-11.0 \mathrm{kcal} \mathrm{mol}^{-1}$ and for aniline from $-25.1 \mathrm{kcal} \mathrm{mol}^{-1}$ to $-11.0 \mathrm{kcal} \mathrm{mol}{ }^{-1}$. Clearly, the $\pi$ orbitals of the phenyl ring can also interact with the perpendicular substituent and the $\pi$ delocalization is therefore not switched off completely (see Fig. S1 and S2 in the ESI, $\dagger$ for the MO diagrams for the perpendicular conformation).

After this explanation of the activating and deactivating effects of the $\mathrm{NH}_{2}$ and $\mathrm{NO}_{2}$ substituents on the benzene ring based on the MO diagrams, we would also like to understand the directionality of the electrophilic attack. Recently, Fievez et al. ${ }^{10 c}$ showed that the orbital interaction is the driving force towards selectivity in electrophilic aromatic substitution for activating substituents, but it is not the main factor for the $\mathrm{NO}_{2}$ substituent. They studied the interaction energy and its components (eqn (1)) between monosubstituted benzene derivatives and a model electrophile at the onset of the reaction in a plane parallel to the molecular plane.

Here, we would like to analyze the molecular orbitals of the substituted benzenes in terms of the contribution of the $2 \mathrm{p}_{z}$ orbitals on the carbon, nitrogen and oxygen atoms to the molecular $\pi$ orbitals, allowing us to explain the directionality from the molecular orbital perspective (see Fig. 3). The high contribution of a $2 \mathrm{p}_{z}$ orbital on a certain carbon atom to the $\pi_{\text {Hомо of the substituted benzene will direct the electrophilic }}$ attack towards that atom because of the larger overlap between the accepting orbital of the electrophile and the $\pi_{\text {номо of the }}$ substituted benzene. The most favorable interaction occurs at the atom with the highest $2 \mathrm{p}_{z}$ contribution to the $\pi_{\text {номо }}$.

Aniline has only one highest occupied $\pi$ orbital at $-4.6 \mathrm{eV}$ with the largest gross Mulliken contributions on the meta $(14 \%)$ and the para $(22 \%)$ positions. The electrophilic attack will therefore occur at these positions. Nitrobenzene has two almost degenerate highest occupied $\pi$ orbitals at $-6.9 \mathrm{eV}$ and $-7.0 \mathrm{eV}$. The $\pi_{\text {номо }}$ directs the electrophilic attack towards ortho and meta positions with $2 \mathrm{p}_{z}$ contributions of $23 \%$ on these two positions, and the $\pi_{\mathrm{HOMO}-1}$ towards the para position with a $2 \mathrm{p}_{z}$ contribution of $31 \%$ on the para (contributions on the ortho and meta positions are small, $5 \%$ and $8 \%$ respectively). Thus, the $\pi$ orbitals of nitrobenzene are deactivated (because they are low-lying) and the experimentally observed meta directing effect of the nitro substituent for electrophilic aromatic substitution cannot be explained from the character of the $\pi_{\text {HOMO }}$ and $\pi_{\text {HOMO-1 }}$.

\section{VDD charge analysis}

Complementary to the KS-MO analysis and the EDA, we have also investigated the VDD atomic charges (eqn (3)) and charge rearrangements (eqn (4)) on the phenyl ring due to the substituent effects to predict the regioselectivity of electrophilic substitution and explain the reactivity of the aromatic ring. Fig. 4 displays the VDD atomic charges (eqn (3)) for benzene, nitrobenzene and aniline, which are the differences between the final density and the density of the promolecule (the sum over spherical atomic densities). The comparison of the VDD atomic charges shows that aniline has a more negative charge than benzene at the ortho and para positions, -78 and -74 milli-electrons, respectively, compared to only -48 millielectrons in benzene. This is in line with the large amplitudes of the $\pi_{\text {Hомо }}$ on the ortho and para carbon atoms. Nitrobenzene has at all positions a less negative charge than benzene, which is in line with the deactivating properties of the nitro group. The meta position in nitrobenzene is slightly more negative (-41 milli-electrons) than the ortho and para positions ( -34 and -28 milli-electrons). Note that the differences in aniline are larger than in nitrobenzene. 

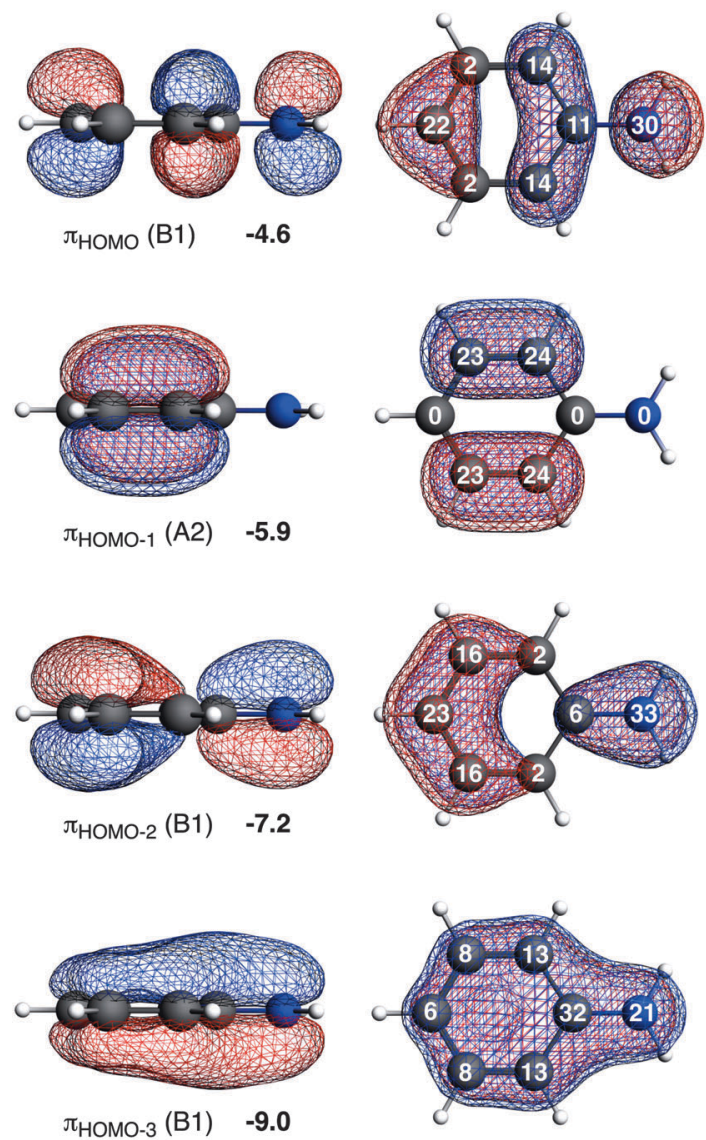
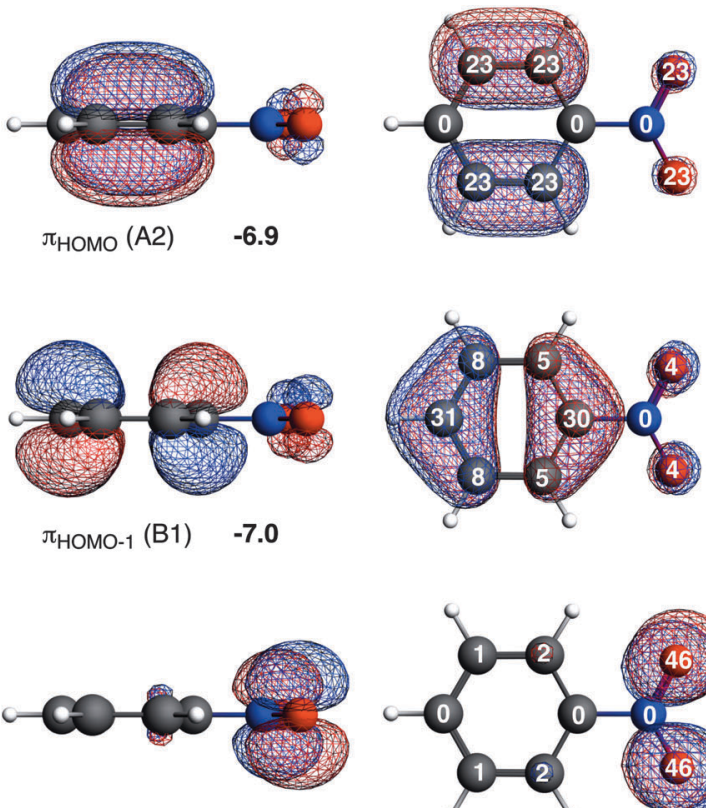

$\pi_{\text {Hомо-2 }}(\mathrm{A} 2) \quad-7.6$
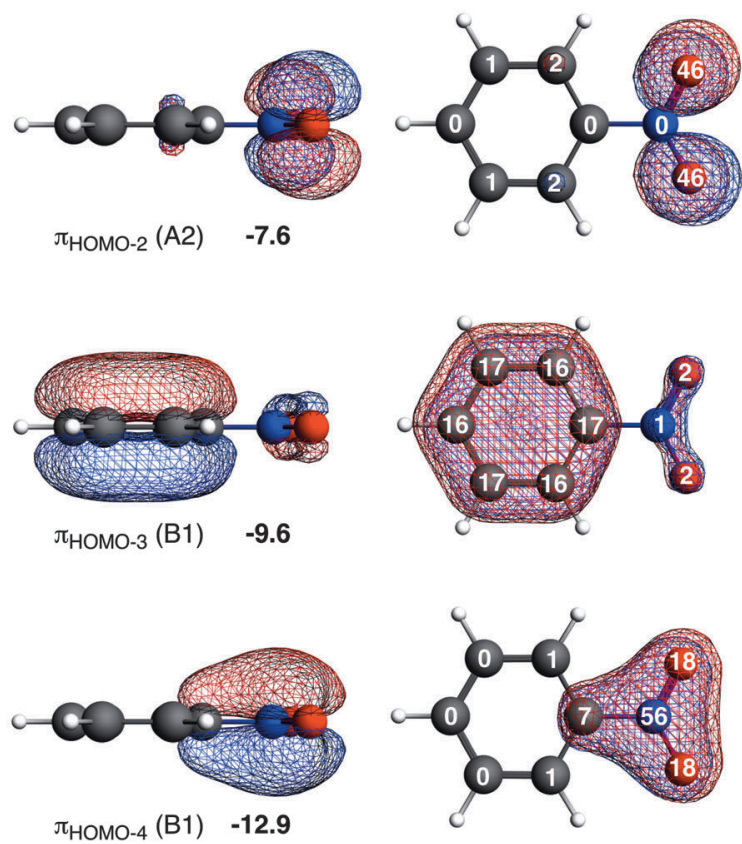

Fig. 3 The $\pi$ orbitals of aniline (left) and nitrobenzene (right) in A2 and B1 representation. The energies of the molecular orbitals are given in eV (black) and the gross Mulliken $2 \mathrm{p}_{z}$ contributions to $\mathrm{MO}$ are given in white on the atom (in percentages).
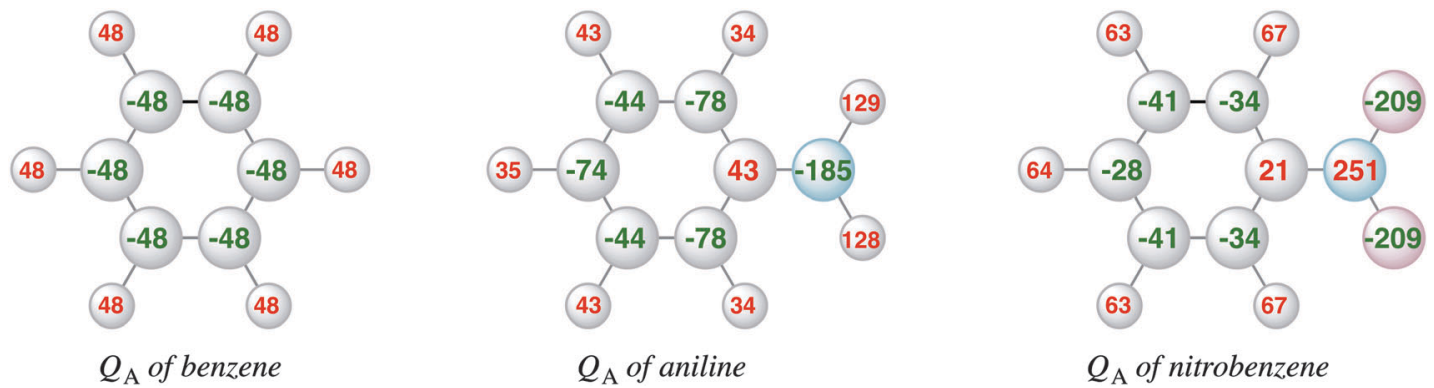

Fig. 4 VDD atomic charges (milli-electrons) of benzene, aniline and nitrobenzene (eqn (3)).

The VDD charge rearrangements, as defined in eqn (4), allows analysis of the charge redistributions within two polyatomic fragments when a chemical bond is formed between these two molecular fragments. Furthermore, it allows decomposition of the total changes into the components of different irreducible representations. In Fig. 5, the VDD charge rearrangements $(\Delta Q)$ due to the formation of the $\mathrm{C}-\mathrm{N}$ bond in aniline and nitrobenzene are given. The bond formation causes 

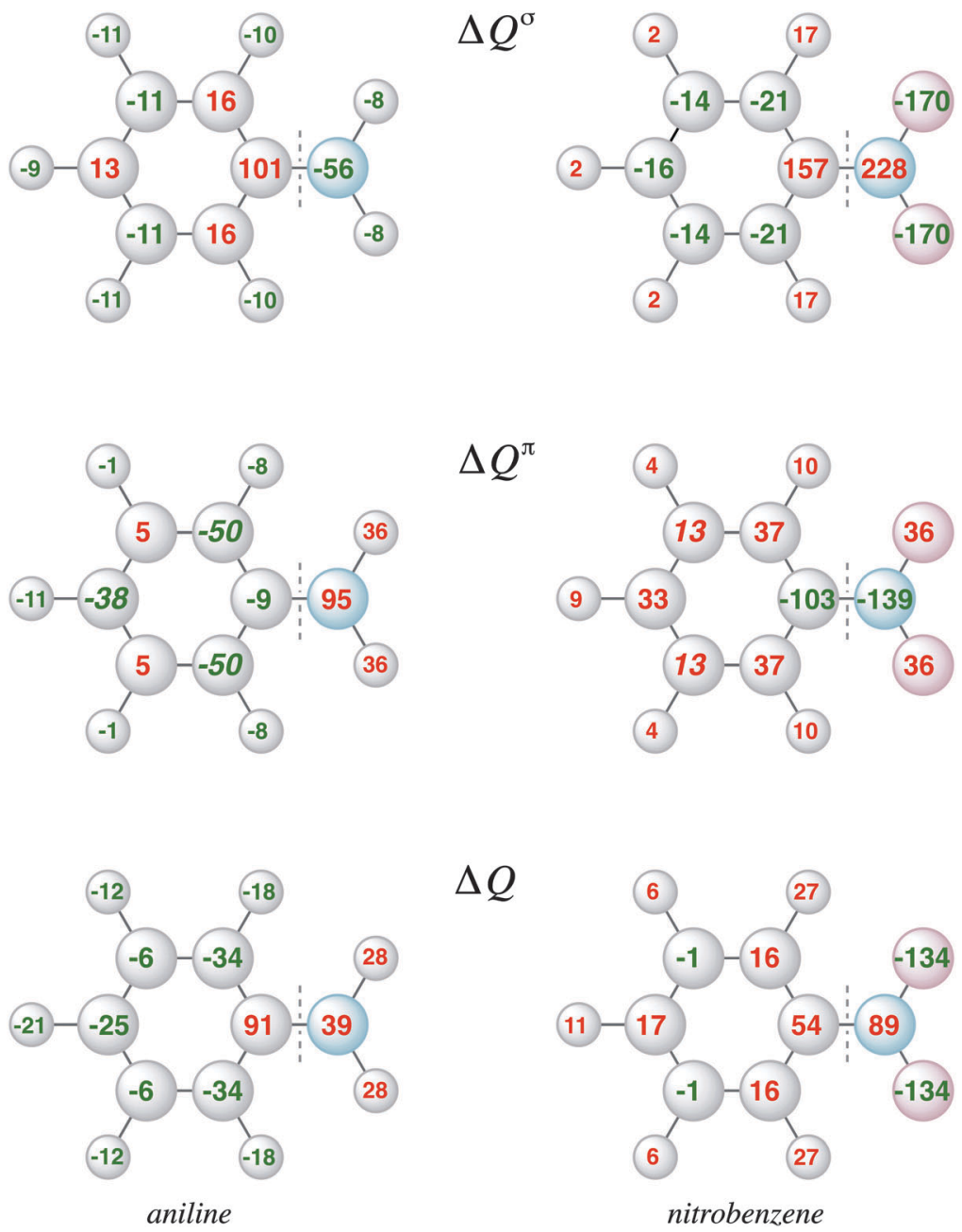

Fig. 5 VDD electronic redistribution $(\Delta Q)$ and the partitioning in the $\Delta Q^{\sigma}$ and $\Delta Q^{\pi}$ components caused by the formation of the $\mathrm{C}-\mathrm{N}$ bond in aniline (left) and nitrobenzene (right) from the fragments $\mathrm{Ph} \cdot$ and $\bullet \mathrm{NH}_{2}$ and $\bullet \mathrm{NO}_{2}$ respectively.

the phenyl ring of aniline to be activated with the largest electronic charge accumulations on the ortho and para positions, and the phenyl ring of nitrobenzene to be deactivated with the smallest electronic charge depletions at the meta positions. Decomposition into $\sigma$ and $\pi$ charge rearrangements, shown in Fig. 5 , reveals that the $\pi$ electronic system, and thus the $\pi$ bond formation, is responsible for the regioselectivity of electrophilic substitution, which is in line with previous research. ${ }^{6 c}$ Negative numbers on the atoms mean an accumulation of $\pi$-electron density on those atoms and positive numbers mean a depletion of $\pi$-electron density at atoms. The $\pi \mathrm{C}-\mathrm{N}$ bond formation in aniline causes $\Delta Q^{\pi}$ to become more negative at the ortho and para positions ( -50 and -38 milli-electrons) experimentally leading to a mixture of ortho and para products, and in nitrobenzene to become more positive at all positions, but less positive at the meta position (only 13 millielectrons are lost at the meta position), thus the nitro group is a deactivating meta-directing substituent. ${ }^{15,16}$ The VDD electronic rearrangements are in line with the experimentally observed regioselectivity of electrophilic aromatic substitution. To determine which factor is more important, orbital interactions or charge redistribution, an additional investigation of the transition state of an electrophile with the substituted benzene is necessary.

Moreover, the VDD charge rearrangements allow for decomposition into the charge rearrangements caused by the Pauli repulsion and orbital interactions. As aniline and nitrobenzene are $C_{2 \mathrm{v}}$ symmetric molecules, we decomposed the $\pi$ charge rearrangements into the $\mathrm{A} 2$ and $\mathrm{B} 1$ contributions. Only the $\mathrm{B} 1$ charge rearrangements are caused by the $\mathrm{C}-\mathrm{N}$ bond formation, whereas the A2 charge rearrangements are only due to polarization (no A2 orbital has amplitude on the atoms lying on the $C_{2}$ symmetry axis). Fig. 6 and 7 clearly show that the directionality of the electrophilic substitution is caused by the B1 charge rearrangements in the orbital interactions, $\Delta Q_{\mathrm{oi}}^{\mathrm{B} 1}$. The largest charge accumulations of $\Delta Q_{o i}^{\mathrm{B} 1}$ are at the ortho and para positions for aniline and the largest charge depletions of $\Delta Q_{\mathrm{oi}}^{\mathrm{B} 1}$ are at the ortho and para positions for nitrobenzene. For aniline, this finding confirms our results from the molecular orbital analysis, whereas for nitrobenzene the VDD charge 


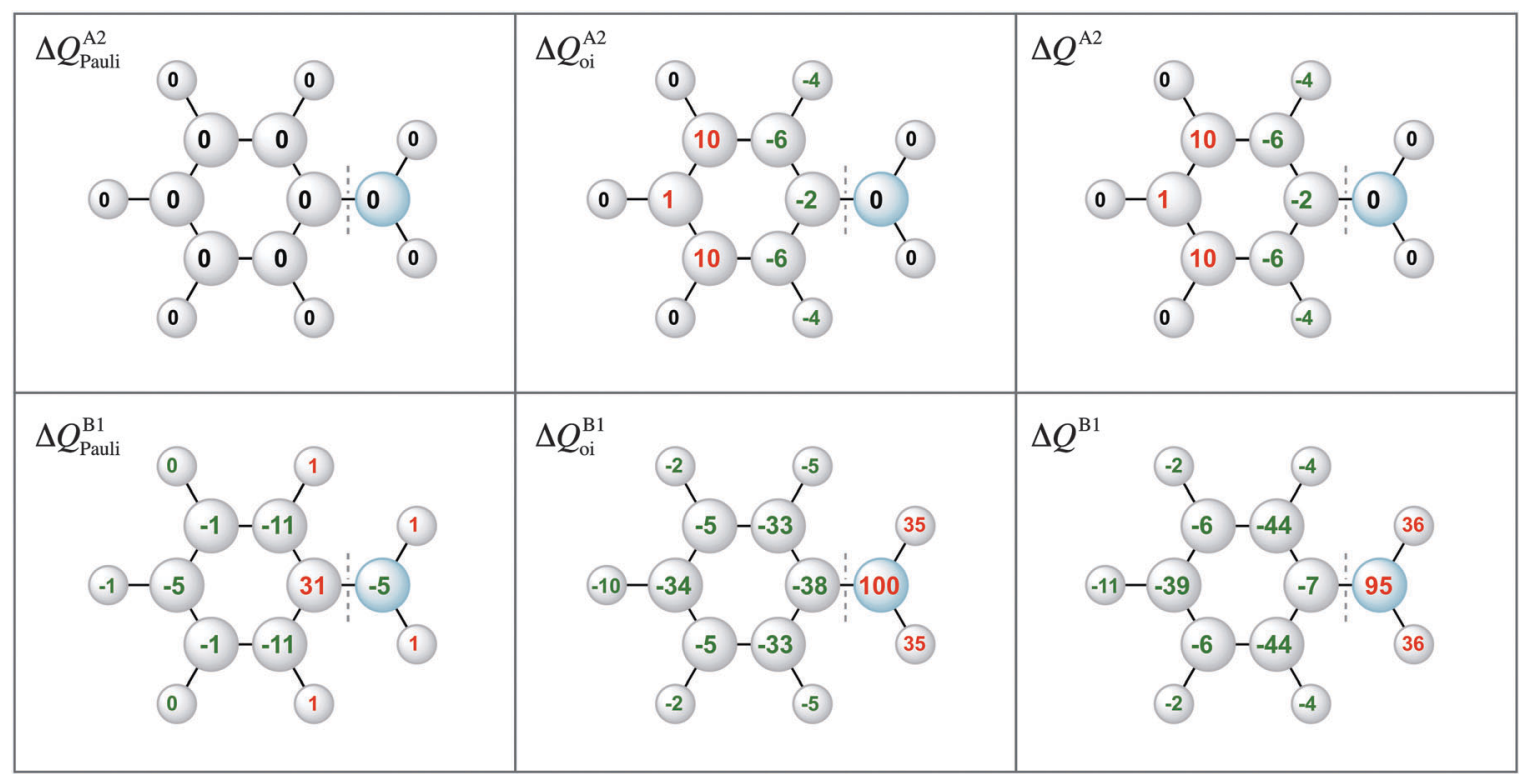

Fig. 6 VDD electronic redistribution $(\Delta Q)$ in the A2, B1 irreducible representations of the $\pi$ system due to Pauli repulsion and the orbital interaction for aniline caused by the formation of the $\mathrm{C}-\mathrm{N}$ bond from the fragments $\mathrm{Ph} \bullet$ and $\bullet \mathrm{NH}_{2}$.

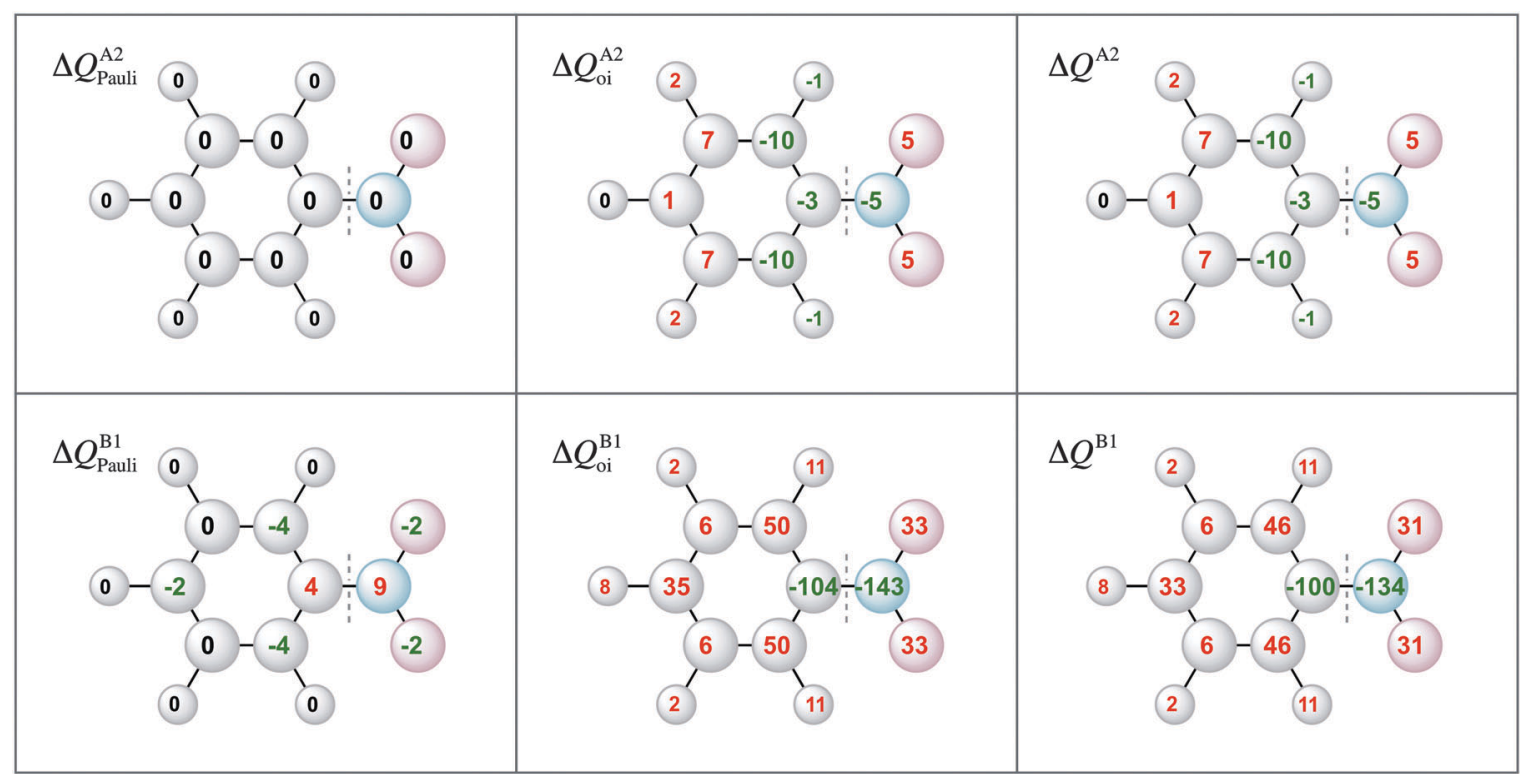

Fig. 7 VDD electronic redistribution $(\Delta Q)$ in the $A 2$, B1 irreducible representations of the $\pi$ system due to Pauli repulsion and the orbital interaction for nitrobenzene caused by the formation of the $\mathrm{C}-\mathrm{N}$ bond from the fragments $\mathrm{Ph} \bullet$ and $\bullet \mathrm{NO}_{2}$.

rearrangements are essential to pinpoint the orbitals responsible for the directionality, namely the B1 orbitals are responsible for the $\mathrm{C}-\mathrm{N}$ bond formation.

\section{Conclusions}

In this paper, we studied using density functional theory the substituent effect of $\mathrm{NH}_{2}$ and $\mathrm{NO}_{2}$ groups on the electronic system of benzene caused by the formation of the $\mathrm{C}-\mathrm{N}$ bond. The computations revealed that the $\mathrm{C}-\mathrm{N}$ bond in aniline is stronger and shorter than in nitrobenzene. With our quantitative Kohn-Sham molecular orbital (KS-MO) model and the corresponding energy decomposition analysis (EDA) we explained that the $\mathrm{NH}_{2}$ group can approach the phenyl ring closer than the $\mathrm{NO}_{2}$ group because there is less Pauli repulsion between the hydrogen atoms of $\mathrm{NH}_{2}$ and the hydrogen atoms of the phenyl radical at the ortho positions, whereas these 
hydrogen atoms experience Pauli repulsion with the lone pairs of the oxygen atoms of $\mathrm{NO}_{2}$. We separated the inductive and resonance effects. The $\sigma$ component of the $\mathrm{C}-\mathrm{N}$ bond formation shows for both substituents the inductive effect whereby the phenyl ring donates electronic density to the substituent. In the $\pi$ electronic system, the effects of the substituents are opposite: $\mathrm{NH}_{2}$ donates the electronic charge, whereas $\mathrm{NO}_{2}$ accepts the electronic charge from the $\pi$ system of the phenyl radical.

The donor-acceptor interactions from the $\pi_{\text {номо }}$ of ${ }^{\bullet} \mathrm{NH}_{2}$ to the $\pi_{\mathrm{LUMO}}$ of the phenyl radical for the $\mathrm{C}-\mathrm{N}$ bond formation in aniline are accompanied by the repulsive interaction between the two $\pi$ HOMOs on the two fragments. It is this repulsive interaction between the occupied orbitals, which pushes up the $\pi_{\text {Hомо }}$ on the phenyl ring of aniline and activates it to electrophilic substitution. The directionality of aniline can be understood from the $2 \mathrm{p}_{z}$ contributions (located on the unsubstituted carbon atoms) to the $\pi_{\text {номо }}$ of aniline, which have the largest amplitude at the ortho and para positions.

In the case of nitrobenzene, the donor-acceptor interactions lead to a lowering of the $\pi_{\text {номо }}$ on the phenyl ring, which deactivates this orbital. Further inspection of the $\pi_{\text {номо }}$ and $\pi_{\mathrm{HOMO}-1}$ orbitals does not explain the directionality of nitrobenzene clearly. It is the VDD charge analysis which shows that the $\pi$ electronic rearrangements due to $\mathrm{C}-\mathrm{N}$ bond formation in nitrobenzene are responsible for the largest deactivation at the ortho and para positions of nitrobenzene, making the nitro group meta directing for electrophilic aromatic substitution.

\section{Acknowledgements}

O. A. S., H. S. and T. M. K. gratefully acknowledge the Foundation for Polish Science for supporting this work under the MPD/ 2010/4 project "Towards Advanced Functional Materials and Novel Devices - Joint UW and WUT International PhD Programme". H. S. and T. M. K. thank the National Science Centre and the Ministry of Science and Higher Education of Poland for supporting this work under grant no. UMO-2013/11/B/ST4/ 00531. C. F. G. acknowledges the financial support from the Netherlands Organization for Scientific Research NWO.

\section{References}

1 (a) M. B. Smith, March's Advanced Organic Chemistry: Reactions, Mechanisms, and Structure, Wiley, New Jersey, 7th edn, 2013; (b) F. A. Carey, Organic Chemistry, McGraw-Hill Higher Education, 2008; (c) P. Y. Bruice, Organic Chemistry, Pearson/ Prentice Hall, 2004; (d) F. A. Carey and R. J. Sundberg, Advanced Organic Chemistry, Part A: Structure and Mechanisms, Springer, New York, 2007; (e) G. N. Lewis, J. Am. Chem. Soc., 1916, 38, 762-785.

2 (a) F. Bernardi, M. Guerra and G. F. Pedulli, Tetrahedron, 1978, 34, 2141-2146; (b) R. F. Johnston and J. C. Cooper, THEOCHEM, 1991, 82, 297-307; (c) R. R. Monaco and W. C. Gardiner, J. Phys. Org. Chem., 1995, 8, 629-636.
3 (a) L. P. Hammett, J. Am. Chem. Soc., 1937, 59, 96-103; (b) L. P. Hammett, Physical Organic Chemistry, McGraw-Hill, New York, 1st edn, 1940, 2nd edn, 1970.

4 (a) C. Hansch, A. Leo and R. W. Taft, Chem. Rev., 1991, 91, 165-195; (b) T. M. Krygowski and B. T. Stpień, Chem. Rev., 2005, 105, 3482-3512; (c) O. Exner and S. Bohm, Curr. Org. Chem., 2006, 10, 763-778.

5 (a) K. Fukui and H. Fujimoto, Frontier Orbitals and Reactions Paths, World Scientific, Singapore, 1997; (b) M. J. S. Dewar, THEOCHEM, 1989, 200, 301-323; (c) H. Hirao and T. Ohwada, J. Phys. Chem. A, 2003, 107, 2875-2881.

6 (a) O. Exner and T. M. Krygowski, Chem. Soc. Rev., 1996, 25, 71-75; (b) P. Politzer, L. Abrahmsen and P. Sjoberg, J. Am. Chem. Soc., 1984, 106, 855-860; (c) J. P. Ritchie, Tetrahedron, 1988, 44, 7465-7478; (d) S. Irle, T. M. Krygowski, J. E. Niu and W. H. E. Schwarz, J. Org. Chem., 1995, 60, 6744-6755.

7 (a) F. M. Bickelhaupt and E. J. Baerends, Kohn-Sham Density Functional Theory: Predicting and Understanding Chemistry, in Rev. Comput. Chem., ed. K. B. Lipkowitz and D. B. Boyd, Wiley, New York, 2000, vol. 15, pp. 1-86; (b) T. Ziegler and A. Rauk, Theor. Chim. Acta, 1977, 46, 1-10; (c) T. Ziegler and A. Rauk, Inorg. Chem., 1979, 18, 1558-1565; (d) K. Morokuma, J. Chem. Phys., 1971, 55, 1236.

8 (a) L. Guillaumes, S. Simon and C. Fonseca Guerra, ChemistryOpen, 2015, 4, 318-327; (b) C. Fonseca Guerra, F. M. Bickelhaupt, J. G. Snijders and E. J. Baerends, Chem. - Eur. J., 1999, 5, 3581-3594; (c) C. Fonseca Guerra and F. M. Bickelhaupt, Angew. Chem., Int. Ed., 2002, 41, 2092-2095; (d) C. Fonseca Guerra, H. Zijlstra, G. Paragi and F. M. Bickelhaupt, Chem. - Eur. J., 2011, 17, 12612-12622.

9 (a) L. P. Wolters and F. M. Bickelhaupt, ChemistryOpen, 2012, 1, 96-105; (b) L. P. Wolters, N. W. G. Smits and C. Fonseca Guerra, Phys. Chem. Chem. Phys., 2015, 17, 1585-1592.

10 (a) F. M. Bickelhaupt, J. Comput. Chem., 1999, 20, 114-128; (b) F. M. Bickelhaupt, E. J. Baerends and N. M. M. Nibbering, Chem. - Eur. J., 1996, 2, 196; (c) T. Fievez, B. Pinter, P. Geerlings, F. M. Bickelhaupt and F. De Proft, Eur. J. Org. Chem., 2011, 2958; (d) G. T. de Jong and F. M. Bickelhaupt, ChemPhysChem, 2007, 8, 1170-1181.

11 (a) S. C. A. H. Pierrefixe and F. M. Bickelhaupt, J. Phys. Chem. A, 2008, 112, 12816-12822; (b) S. C. A. H. Pierrefixe and F. M. Bickelhaupt, Aust. J. Chem., 2008, 61, 209-215; (c) J. R. Mulder, C. Fonseca Guerra, J. C. Slootweg, K. Lammertsma and F. M. Bickelhaupt, J. Comput. Chem., 2016, 37, 304-313; (d) I. Fernandez and G. Frenking, J. Org. Chem., 2006, 71, 2251-2256.

12 (a) G. te Velde, F. M. Bickelhaupt, S. J. A. van Gisbergen, C. Fonseca Guerra, E. J. Baerends, J. G. Snijders and T. Ziegler, J. Comput. Chem., 2001, 22, 931-967; (b) E. J. Baerends, et al., $A D F$ 2013, SCM, Theoretical Chemistry, Vrije Universiteit, Amsterdam, The Netherlands, http://www.scm.com; (c) A. D. Becke, Phys. Rev. A: At., Mol., Opt. Phys., 1988, 38, 3098-3100; (d) C. Lee, W. Yang and R. G. Parr, Phys. Rev. B: Condens. Matter Mater. Phys., 1988, 37, 785-789; (e) J. G. Snijders, E. J. Baerends and P. Vernooijs, At. Data Nucl. Data Tables 26, 1981, 483. 
13 H. Szatyłowicz, T. M. Krygowski and P. Hobza, J. Phys. Chem. A, 2007, 111, 170-175.

14 (a) F. M. Bickelhaupt, N. J. R. van Eikema Hommes, C. Fonseca Guerra and E. J. Baerends, Organometallics, 1996, 15, 2923-2931; (b) C. Fonseca Guerra, J. W. Handgraaf, E. J. Baerends and F. M. Bickelhaupt, J. Comput. Chem., 2004, 25, 189-210.
15 (a) P. V. Vyas, A. K. Bhatt, G. Ramachandraiah and A. V. Bedekar, Tetrahedron Lett., 2003, 44, 4085-4088; (b) S. Patai, The Chemistry of the Amino Group, Wiley, New York, 1968, pp. 250-265.

16 S. Rozen and O. Lerman, J. Org. Chem., 1993, 58, 239-240. 